\title{
Age-related changes in muscle strength and spinal kyphosis angles in an elderly Japanese population
}

\author{
This article was published in the following Dove Press journal: \\ Clinical Interventions in Aging \\ 20 February 2017 \\ Number of times this article has been viewed
}

\section{Yuji Kasukawa \\ Naohisa Miyakoshi \\ Michio Hongo \\ Yoshinori Ishikawa \\ Daisuke Kudo \\ Masazumi Suzuki \\ Takashi Mizutani \\ Ryouta Kimura \\ Yuichi Ono \\ Yoichi Shimada}

Department of Orthopedic Surgery, Akita University Graduate School of Medicine, Akita, Japan
Correspondence: Yuji Kasukawa Department of Orthopedic Surgery, Akita University Graduate School of Medicine, I-I-I Hondo, Akita 0I0-8543, Japan

Tel $+8|\quad| 88846 \mid 48$

$\mathrm{Fax}+81188362617$

Email kasukawa@doc.med.akita-u.ac.jp
Abstract: Lumbar kyphosis and the decreased mobility of the lumbar spine increase the risk of falls and impair both the quality of life and the ability to perform activities of daily living. However, in the elderly Japanese population, little is known about the age-related changes and sex-related differences in muscle strength, including of the upper and lower extremities and back extensors. An adequate kyphotic or lordotic angle has also not been determined. In this study, we evaluated the age-related changes in muscle strength and spinal kyphosis in 252 males and 320 females $\geq 50$ years of age. Grip, back extensor, hip flexor, and knee extensor strength; thoracic and lumbar kyphosis; and spinal inclination in the neutral standing position were assessed, together with the range of motion of the thoracic and lumbar spine and spinal inclination. Grip strength, back extensor strength, and the strength of the hip flexors and knee extensors decreased significantly with aging, both in males $(P<0.0001)$ and in females $(P=0.0015$ to $P<0.0001)$. The lumbar but not the thoracic kyphosis angle decreased significantly with aging, only in females $(P<0.0001)$. Spinal inclination increased significantly with aging in both males $(P=0.002)$ and females $(P<0.0001)$. Back extensor strength and the thoracic kyphosis angle were significant variables influencing the lumbar kyphosis angle in both sexes. Spinal inclination correlated significantly with both the lumbar kyphosis angle and hip flexor strength in males, as well as with the lumbar kyphosis angle in females.

Keywords: aging, gender, grip strength, back extensor strength, spinal curvature

\section{Introduction}

Aging is associated with progressive physiologic changes that lead to deterioration of the structure and function of the musculoskeletal system. ${ }^{1,2}$ This results in a decline in the functional performance of older adults and often in the eventual need for nursing care or support. ${ }^{3,4}$ Thus, in the elderly, the maintenance of good physical and functional performance is critical to preserve independence and decrease the risk of disability.

Declining muscle strength in the elderly is associated with poor physical performance, an increased risk of falls and disability, poor quality of life (QoL), and increased mortality..$^{5-9}$ The age-related decline in muscle strength ${ }^{1,3}$ involves both the upper and lower extremities, as well as the lumbar extensors. In the latter muscles, a 50\% reduction between the third and sixth decades of life has been reported. ${ }^{10,11}$ However, in the elderly Japanese population, age-related changes and sex-related differences in muscle strength, including that of the upper and lower extremities and back extensors, have not been well studied.

Lumbar kyphosis and the mobility of the lumbar spine are additional important parameters that contribute to determining the QoL of the elderly. An increase in the thoracic kyphosis angle during aging has also been reported, ${ }^{12,13}$ especially in females. ${ }^{14}$ Previous studies of elderly Japanese have shown that lumbar kyphosis, 
decreased mobility of the lumbar spine, and an increase in spinal inclination, but not thoracic kyphosis or thoracic spine mobility, are also related to an increased risk of falls. ${ }^{9,15}$ In a previous work, we demonstrated that back extensor strength is a significant determinant of lumbar kyphosis and the mobility of the lumbar spine. ${ }^{8,16}$ The purpose of this study was to evaluate the age-related changes and sex-related differences in muscle strength in the upper and lower extremities as well as the trunk, their associations with spinal alignment and mobility, and the factors significantly associated with lumbar kyphosis and spinal inclination in elderly Japanese. We therefore measured grip, back extensor, hip flexor, and knee extensor strength; the kyphotic angles of the thoracic and lumbar spine; and spinal inclination in community-dwelling Japanese males and females 50 years of age and older.

\section{Methods}

\section{Patients and study design}

The 252 males and 320 females who participated in this study were $\geq 50$ years of age. All 572 participants underwent a medical checkup at municipal health centers between 2009 and 2014. After receiving an explanation of the measurements of muscle strength and spinal kyphosis angle, all subjects provided written informed consent to participate. The study protocol was approved by the ethics committee of Akita University Graduate School of Medicine.

\section{Measurement of muscle strength}

Grip strength was measured on the dominant and nondominant sides using a dynamometer (TTM Dynamometer; Tsutsumi, Tokyo, Japan), with the patient in the upright position. The test was performed twice, and the average of the right and left sides then determined. Muscle strength of the lower extremities, including hip flexors and knee extensors, was measured using a handheld dynamometer (Commander ${ }^{\mathrm{TM}}$ PowerTrack II ${ }^{\mathrm{TM}}$ Handheld Dynamometer; Nihon Medix Co, Ltd, Matsudo, Japan). The strength of the muscle groups of the lower extremities was measured twice and the average of the bilateral measurements was then determined. Isometric back extensor strength in the prone position was measured using a strain gauge dynamometer (DPU-1000N Digital Force Gauge; Imada, Toyohashi, Japan). The patient's position was aligned with the table and a strain gauge dynamometer was placed in the mid portion (at the inferior aspect of the scapula) of his or her back. The patient was then asked to lift his/her upper trunk as much as possible. Maximum strength was then recorded using the strain gauge. Measurements were performed three times and the maximum value then selected, as previously described. ${ }^{16}$ The coefficient of variation, as an indicator of the precision of the measurement, was $2.3 \%{ }^{8}$

\section{Thoracic and lumbar kyphosis angles and mobility}

The kyphosis angle of both the thoracic (T1-T12) and the lumbar (L1-S1) spine (Figure 1) was measured using a computerized measurement device for surface curvature (SpinalMouse $^{\circledR}$; Idiag, Volkerswill, Switzerland) (Figure 1A), with the patient in the upright position. Spinal inclination, defined as the angle between the line from the center of T1 to $\mathrm{S} 1$ and a vertical line originating at S1, was also measured (Figure 1B). By sliding the measurement device along the spinal curve, the spinal kyphosis angles could be calculated. The results were displayed on a computer monitor. Repeating this process with the patient in spinal flexion and extension was interpreted as a measurement of spinal mobility (Figure 1A). The mobility of the spinal inclination reflects the mobility of the trunk, including thoracic, lumbar, and sacral/hip mobility, and was also measured at maximum flexion and extension (Figure 1B). The intraclass coefficients for the curvature measurement with the SpinalMouse were 0.92-0.95. ${ }^{17}$

\section{Statistical analyses}

The results are expressed as the mean (standard deviation). A Kolmogorov-Smirnov test was performed to confirm the normal distributions of the data for males and females. Intergroup, age-dependent differences in males and females were assessed using a one-way analysis of variance (ANOVA), followed by Scheffe's multiple comparison method as a post hoc test. Correlations between the parameters were analyzed using Pearson's method. Parameters significantly associated with lumbar kyphosis and spinal inclination were identified in a multiple regression analysis. Differences with a $P$-value $<0.05$ were considered statistically significant. All statistical analyses were performed using Statistical Package for the Biosciences software (SPBS version 9.54, developed by Murata K et al., Akita University Graduate School of Medicine, Akita, Japan). ${ }^{18}$

\section{Results}

\section{Participant characteristics}

Table 1 presents the physical characteristics of the participants. The heights and body weights of males and females decreased significantly with aging $[F(3,248)=15.966$, $P<0.0001$ and $F(3,248)=17.138, P<0.0001$ in males, and $F(3,316)=26.763, P<0.0001$ and $F(3,316)=4,784, P=0.0028$ in females, respectively], as determined by ANOVA. Body 


\begin{tabular}{|l|rrr|rrr|}
\hline A Segment & Upr & Flex & Ext & U-F & U-E & E-F \\
\hline Th1/2 & -9 & 0 & 36 & 9 & 45 & -36 \\
\hline Th2/3 & -16 & 1 & 6 & 17 & 22 & -5 \\
\hline Th3/4 & 6 & 7 & 3 & 0 & -3 & 4 \\
\hline Th4/5 & 7 & 2 & -3 & -5 & -10 & 5 \\
\hline Th5/6 & 8 & 2 & 3 & -6 & -5 & -1 \\
\hline Th6/7 & 3 & 2 & 0 & -1 & -3 & 2 \\
\hline Th7/8 & 4 & 5 & 3 & 1 & -1 & 3 \\
\hline Th8/9 & 3 & 3 & -1 & 0 & -5 & 4 \\
\hline Th9/10 & 2 & 6 & 1 & 4 & -1 & 6 \\
\hline Th10/11 & 5 & 6 & -1 & 1 & -6 & 7 \\
\hline Th11/12 & -3 & 5 & 6 & 8 & 9 & -1 \\
\hline Th12/L1 & 3 & 6 & -6 & 4 & -9 & 12 \\
\hline L1/2 & -7 & 7 & -6 & 14 & 1 & 13 \\
\hline L2/3 & 6 & -2 & -7 & -8 & -12 & 4 \\
\hline L3/4 & -3 & 3 & 1 & 6 & 4 & 2 \\
\hline L4/5 & -2 & 3 & 10 & 5 & 11 & -6 \\
\hline L5/S1 & -25 & -3 & 9 & 23 & 34 & -11 \\
\hline \hline Sac/Hip & 18 & 84 & -39 & 66 & -56 & 123 \\
\hline ThSp & 11 & 40 & 53 & 29 & 42 & -13 \\
\hline LSp & -29 & 15 & 1 & 43 & 29 & 14 \\
\hline Incl & -3 & 107 & -24 & 110 & -21 & 131 \\
\hline Length & 462 & 486 & 443 & 24 & -20 & 43 \\
\hline
\end{tabular}
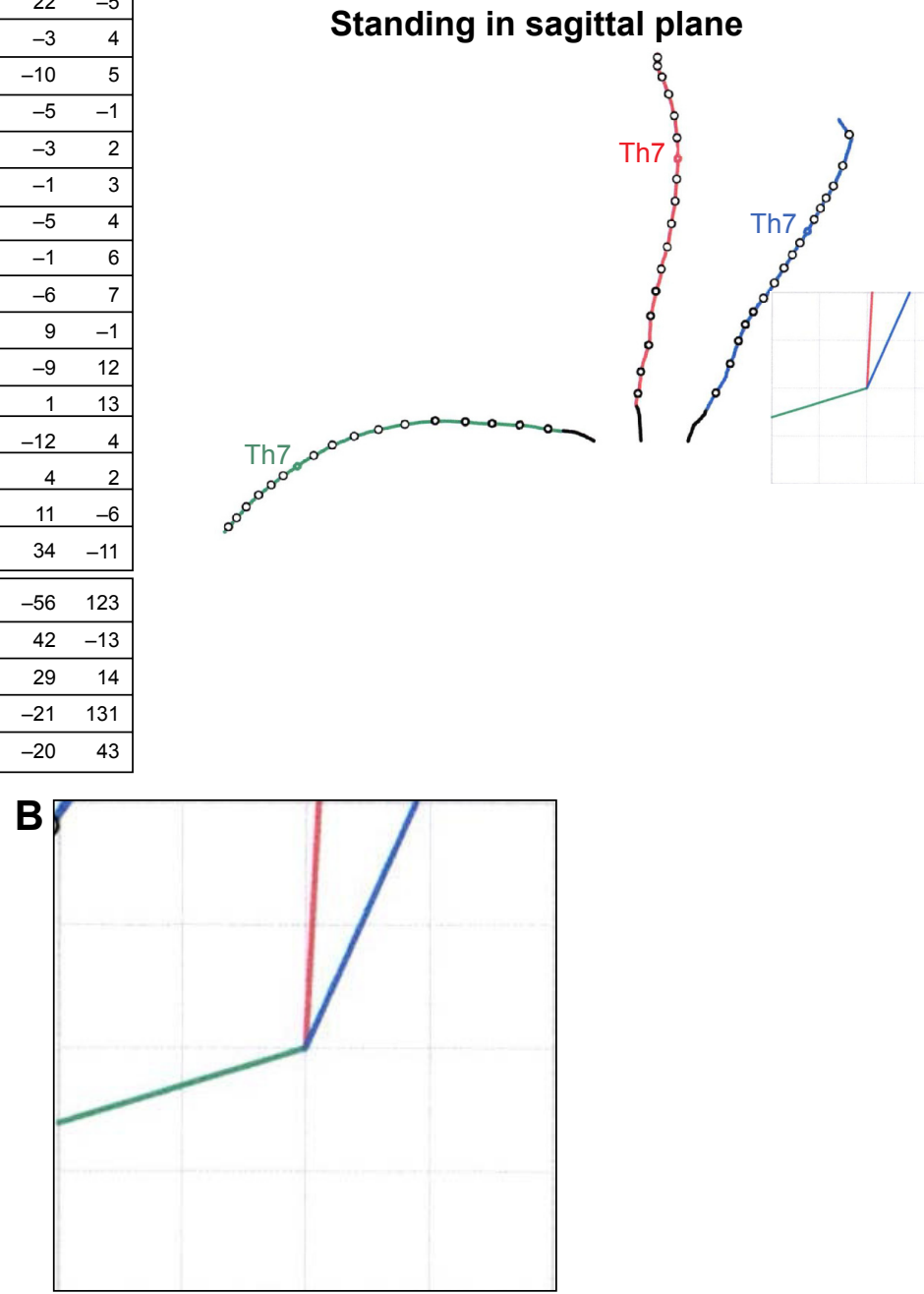

Figure I Thoracic kyphosis, lumbar kyphosis, and spinal inclination angles, measured using the SpinalMouse.

Notes: (A) All three angles were measured using the SpinalMouse software, with the patient in neutral (red line), flexed (green line), and extended (blue line) positions. The mobility of these angles from flexion to extension was calculated using the same software. (B) Spinal inclination was defined as the angle between the line from the center of $\mathrm{TI}$ to SI and a vertical line originating at SI, measured with the patient in neutral (red line), flexed (green line), and extended (blue line) positions.

Abbreviations: Th, thoracic; L, lumbar; Incl, inclination; Upr, upright position; Flex, flexed position; Ext, extended position; U-F, mobility from upright to extended position; U-E, mobility from upright to flexed position; E-F, mobility from extended to flexed position; ThSp, thoracic spine; LSp, lumbar spine.

Table I Age-specific characteristics of the study participants

\begin{tabular}{|c|c|c|c|c|c|c|}
\hline Characteristics & $50 \mathrm{~s}$ & $60 \mathrm{~s}$ & $70 s$ & $80 \mathrm{~s}$ & $\begin{array}{l}F_{3,248} \text { value } \\
\text { of ANOVA }\end{array}$ & $\begin{array}{l}P \text {-value } \\
\text { of ANOVA }\end{array}$ \\
\hline Male, $\mathrm{N}$ & 22 & 79 & 106 & 45 & - & - \\
\hline Height, cm & I66.I (7.I) & $163.2(6.2)$ & I58.6 (6.4) & I $57.8(6.2)^{\mathrm{a}, \mathrm{b}^{\prime}}$ & 15.966 & $<0.0001$ \\
\hline Body weight, kg & $69.6(11.5)$ & $64.6(8.5)$ & $60.2(8.2)^{\mathrm{a}, \mathrm{b}^{\prime \prime}}$ & $56.0(7.7)^{\mathrm{a}, \mathrm{b}}$ & 17.138 & $<0.0001$ \\
\hline BMI & $25.2(3.4)$ & $24.2(2.8)$ & $23.9(2.6)$ & $22.4(2.3)$ & 6.730 & $<0.0001$ \\
\hline Characteristics & $50 \mathrm{~s}$ & $60 \mathrm{~s}$ & $70 s$ & $80 s$ & $\begin{array}{l}F_{3,316} \text { value } \\
\text { of ANOVA }\end{array}$ & $\begin{array}{l}P \text {-value } \\
\text { of ANOVA }\end{array}$ \\
\hline Female, N & 35 & 126 & 125 & 34 & - & - \\
\hline Height, cm & I56.I (6.2) & I $50.5(5.3)^{\mathrm{a}}$ & I $48.7(5.1)^{\mathrm{a}}$ & I $44.7(5.9)^{\mathrm{a}, \mathrm{b}, \mathrm{c}}$ & 26.763 & $<0.0001$ \\
\hline Body weight, kg & $55.9(6.4)$ & $53.9(8.4)$ & $51.3(8.4)^{\mathrm{a}^{\prime}}$ & $50.3(6.8)$ & 4.784 & 0.0028 \\
\hline BMI & $22.9(2.4)$ & $23.8(3.7)$ & $23.2(3.6)$ & $23.9(3.2)$ & 1.073 & 0.3608 \\
\hline
\end{tabular}

Notes: Results of an ANOVA with Scheffe's multiple comparison method. Data are presented as the mean (standard deviation). ${ }^{a} P<0.000 \mathrm{I},{ }^{\prime} \mathrm{P}<0.0 \mathrm{I}$ vs those in their 50 s, ${ }^{\mathrm{b}} \mathrm{P}<0.000 \mathrm{I},{ }^{\mathrm{b}} \mathrm{P}<0.00 \mathrm{I}, \mathrm{b}^{\mathrm{b}} \mathrm{P}<0.0 \mathrm{I}$ vs those in their $60 \mathrm{~s},{ }^{\mathrm{c}} \mathrm{P}<0.0 \mathrm{I}$ vs those in their $70 \mathrm{~s}$.

Abbreviations: ANOVA, analysis of variance; BMI, body mass index. 
mass index (BMI) significantly decreased with age only in males $[F(3,248)=6.730, P<0.0001]$.

\section{Grip, back extensor, hip flexor, and knee extensor strength}

Table 2 presents the results of strength testing of grip, back extensors, hip flexors, and knee extensors. For this analysis, the participants were divided into age groups by decade. Significant decreases in all four parameters occurred with increasing age in both males $[F(3,248)=8.415-26.505$, $P<0.0001]$ and females $[F(3,316)=5.269-26.720, P=0.0015$ to $P<0.0001$ ].

In males, grip, back extensor, hip flexor, and knee extensor strength were significantly lower in participants in their 70 s and 80 s than in those in their 50 s $(P<0.05$ to $P<0.0001$, except knee extensor strength in participants in their 70s) or 60 s $(P<0.05$ and $P<0.0001)$. Grip and back extensor strength was significantly lower in participants in their 80 s than in those in their 70s $(P<0.01$ and $P<0.05$, respectively).

In females, grip, back extensor, and hip flexor strength were significantly lower in participants in their 70s and $80 \mathrm{~s}$ than in those in their 50s $(P<0.05$ to $P<0.0001)$ or $60 \mathrm{~s}$ $(P<0.05$ to $P<0.0001)$. Grip strength was significantly lower in participants in their $60 \mathrm{~s}$ or $80 \mathrm{~s}$ than in those in their $50 \mathrm{~s}$ $(P<0.05)$ or $70 \mathrm{~s}(P<0.05)$. However, knee extensor strength in females was significantly lower only in participants in their 80 s vs those in their 70 s $(P<0.01)$.

\section{Spinal kyphosis angles and spinal mobility}

Table 3 presents the results of the spinal (lumbar and thoracic) kyphosis angle and spinal mobility measurements in males and females.

\section{Males}

The thoracic kyphosis angle $[F(3,248)=2.807, P=0.0403]$ and spinal inclination $[F(3,248)=5.055, P=0.0020]$, but not the lumbar kyphosis angle, increased significantly with aging. Significant decreases with aging also occurred with respect to the mobility of the thoracic $[F(3,248)=2.731, P=0.0444]$ and lumbar $[F(3,248)=6.024, P=0.0006]$ spine, as well as the spinal inclination $[F(3,248)=6.084, P=0.0005]$, as determined in an ANOVA. Spinal inclination was significantly greater in male participants in their $80 \mathrm{~s}$ than in those in their $60 \mathrm{~s}(P<0.01)$ and $70 \mathrm{~s}(P<0.05)$. The mobility of the lumbar spine and the spinal inclination were significantly lower in participants in their $80 \mathrm{~s}$ than in those in either their $60 \mathrm{~s}(P<0.01$ and $P<0.05$, respectively) or their $70 \mathrm{~s}(P<0.01$ and $P<0.01$, respectively).

\section{Females}

The lumbar kyphosis angle $[F(3,316)=8.498, P<0.0001]$ and spinal inclination $[F(3,316)=12.919, P<0.0001]$, but not the thoracic kyphosis angle, increased significantly with aging, as determined by ANOVA. Significant decreases with aging were seen in the mobility of the lumbar spine $[F(3,316)=7.422, P<0.0001]$ and the spinal inclination $[F(3,316)=3.051, P=0.0288]$, as determined in an ANOVA. Both the lumbar kyphosis angle and the spinal inclination were significantly reduced in participants in their $60 \mathrm{~s}$ vs those in their 70s $(P<0.01$ and $P<0.05$, respectively) or 80 s $(P<0.01$ and $P<0.0001$, respectively). The lumbar kyphosis angle was significantly larger in participants in their $80 \mathrm{~s}$ than in those in their $50 \mathrm{~s}(P<0.05)$. Spinal inclination was significantly larger in participants in their 80 s than in those in their 50s $(P<0.0001), 60 \mathrm{~s}(P<0.0001)$, or 70s $(P<0.01)$. Lumbar spine mobility was significantly greater in female

Table 2 Age-specific muscle strength of the study participants

\begin{tabular}{|c|c|c|c|c|c|c|}
\hline Strength, kg & $50 s$ & $60 s$ & $70 s$ & $80 s$ & $\begin{array}{l}F_{3,248} \text { value } \\
\text { of ANOVA }\end{array}$ & $\begin{array}{l}\text { P-value } \\
\text { of ANOVA }\end{array}$ \\
\hline Male, $\mathrm{N}$ & 22 & 79 & 106 & 45 & & \\
\hline Grip & $4 I .8(8.0)$ & $39.4(7.3)$ & $34.6(6.5)^{\mathrm{a}^{\prime}, \mathrm{b}}$ & $30.0(5.4)^{\mathrm{a}, \mathrm{b}, \mathrm{c}}$ & 25.381 & $<0.0001$ \\
\hline Back extensor & $31.4(13.3)$ & $29.2(11.4)$ & $20.6(9.7)^{a^{\prime}, b}$ & I4.6 (7.0) $)^{\mathrm{a}, \mathrm{b}, \mathrm{c}^{\prime}}$ & 26.505 & $<0.0001$ \\
\hline Hip flexor & $21.3(7.2)$ & $20.4(6.5)$ & I6.5 (5.7 $)^{a^{\prime \prime,}, b^{\prime}}$ & $14.7(4.9)^{a^{\prime}, \mathrm{b}}$ & $|3.24|$ & $<0.0001$ \\
\hline Knee extensor & $18.7(5.0)$ & $18.5(6.0)$ & $15.7(5.7)^{b^{\prime \prime}}$ & $13.9(4.6)^{a^{\prime \prime \prime,} b^{\prime}}$ & 8.415 & $<0.0001$ \\
\hline Strength, kg & $50 \mathrm{~s}$ & $60 \mathrm{~s}$ & $70 \mathrm{~s}$ & $80 \mathrm{~s}$ & $\begin{array}{l}F_{3,316} \text { value } \\
\text { of ANOVA }\end{array}$ & $\begin{array}{l}P \text {-value } \\
\text { of ANOVA }\end{array}$ \\
\hline Female, $\mathrm{N}$ & 35 & 126 & 125 & 34 & & \\
\hline Grip & $28.0(5.2)$ & $24.8(4.5)^{a^{\prime \prime}}$ & $22.2(4 . I)^{\mathrm{a}, \mathrm{b}^{\prime}}$ & $19.4(6.2)^{\mathrm{a}, \mathrm{b}, \mathrm{c}^{\prime}}$ & 26.720 & $<0.0001$ \\
\hline Back extensor & $20.1(7.3)$ & I9.| (6.5) & $13.9(6.2)^{a, b}$ & $10.6(7.0)^{\mathrm{a}, \mathrm{b}}$ & 25.813 & $<0.0001$ \\
\hline Hip flexor & I4.8 (4.4) & I4.I (4.3) & $12.5(4.1)^{\mathrm{a}^{\prime \prime \prime}, \mathrm{b}^{\prime \prime}}$ & $11.6(3.2)^{a^{2 \prime \prime}, b^{\prime \prime}}$ & 6.721 & 0.0002 \\
\hline Knee extensor & | 4.6 (4.6) & I5.I (4.8) & I3.6 (5.3) & $11.6(3.8)^{c}$ & 5.269 & 0.0015 \\
\hline
\end{tabular}

Notes: Results of an ANOVA with Scheffe's multiple comparison method. Data are presented as the mean (standard deviation). ${ }^{a} P<0.0001,{ }^{\prime} P<0.001,{ }^{a^{\prime \prime}} P<0.01$, ${ }^{a^{\prime \prime}} P<0.05$ vs those in their $50 \mathrm{~s},{ }^{b} P<0.000 \mathrm{I},{ }^{\prime} P<0.00 \mathrm{I},{ }^{\prime \prime} P<0.05$ vs those in their $60 \mathrm{~s},{ }^{c} P<0.01$, ${ }^{\prime} P<0.05$ vs those in their 70 s.

Abbreviation: ANOVA, analysis of variance. 
Table 3 Age-specific spinal kyphosis angles and spinal mobility of the study participants

\begin{tabular}{|c|c|c|c|c|c|c|}
\hline Characteristics & $50 \mathrm{~s}$ & $60 \mathrm{~s}$ & $70 \mathrm{~s}$ & $80 \mathrm{~s}$ & $\begin{array}{l}F_{3,248} \text { value } \\
\text { of ANOVA }\end{array}$ & $\begin{array}{l}\text { P-value } \\
\text { of ANOVA }\end{array}$ \\
\hline Male, $\mathrm{N}$ & 22 & 79 & 106 & 45 & & \\
\hline \multicolumn{7}{|l|}{ Angle, degree } \\
\hline Thoracic kyphosis & $32.3(16.5)$ & $33.9(14.4)$ & $32.4(13.4)$ & $39.8(18.1)$ & 2.807 & 0.0403 \\
\hline Lumbar kyphosis & $-14.6(8.1)$ & $-13.5(10.9)$ & $-12.9(11.4)$ & $-11.5(13.8)$ & 0.464 & 0.7078 \\
\hline Spinal inclination & $4.9(4.2)$ & $3.2(4.5)$ & $3.8(4.5)$ & $6.4(5.6)^{b^{\prime}, c^{\prime}}$ & 5.055 & 0.0020 \\
\hline \multicolumn{7}{|l|}{ Mobility, degree } \\
\hline Thoracic spine & $27.8(25.4)$ & $27.9(24.9)$ & $19.3(25.1)$ & $17.3(26.4)$ & 2.731 & 0.0444 \\
\hline Lumbar spine & $42.6(14.1)$ & $43.2(18.4)$ & $41.3(14.6)$ & $30.5(20.4)^{b^{\prime}, c}$ & 6.024 & 0.0006 \\
\hline Spinal inclination & $103.1(33.5)$ & II 15.5 (33.8) & I I 7.8 (27.4) & $95.8(35.5)^{\mathrm{b}^{\prime \prime}, \mathrm{c}}$ & 6.084 & 0.0005 \\
\hline Characteristics & $50 \mathrm{~s}$ & $60 \mathrm{~s}$ & $70 \mathrm{~s}$ & $80 s$ & $\begin{array}{l}F_{3,316} \text { value } \\
\text { of ANOVA }\end{array}$ & $\begin{array}{l}\text { P-value } \\
\text { of ANOVA }\end{array}$ \\
\hline Female, $\mathrm{N}$ & (35) & $(126)$ & $(125)$ & (34) & & \\
\hline \multicolumn{7}{|l|}{ Angle, degree } \\
\hline Thoracic kyphosis & $32.8(11.6)$ & $32.6(14.3)$ & $31.3(15.6)$ & $34.0(21.3)$ & 0.347 & 0.7914 \\
\hline Lumbar kyphosis & $-18.2(8.3)$ & $-18.3(9.3)$ & $-13.5(10.6)^{b^{\prime}}$ & $-10.1(14.3)^{a^{\prime}, b^{\prime}}$ & 8.498 & $<0.0001$ \\
\hline Spinal inclination & $2.2(4.9)$ & $2.0(4.2)$ & $3.7(4.2)^{\mathrm{b}^{\prime \prime}}$ & $7.5(7.6)^{a, b, c}$ & 12.919 & $<0.0001$ \\
\hline \multicolumn{7}{|l|}{ Mobility, degree } \\
\hline Thoracic spine & $23.9(31.3)$ & $23.2(34.6)$ & $19.8(25.9)$ & 21.4 (19.1) & 0.339 & 0.7970 \\
\hline Lumbar spine & $50.8(14.8)$ & $48.5(15.2)$ & $41.0(17.0)^{\mathrm{a}^{\prime}, \mathrm{b}^{\prime}}$ & $39.4(16.7)^{a^{\prime}, b^{\prime \prime}}$ & 7.422 & $<0.0001$ \\
\hline Spinal inclination & I $23.5(29.8)$ & I30.| (29.4) & $119.1(34.1)$ & 117.5 (30.9) & 3.051 & 0.0288 \\
\hline
\end{tabular}

Notes: Results of an ANOVA with Scheffe's multiple comparison method. Data are presented as mean (standard deviation). a $P<0.000$ I, ${ }^{a^{\prime}} P<0.05$ vs those in their 50 s, ${ }^{b} P<0.000$ I, ${ }^{\prime} P<0.01$, ${ }^{b \prime} P<0.05$ vs those in their 60 s, ${ }^{c} P<0.0$ I, ${ }^{c} P<0.05$ vs those in their 70 s.

Abbreviation: ANOVA, analysis of variance.

participants in their $50 \mathrm{~s}$ than in those in either their $70 \mathrm{~s}$ $(P<0.05)$ or their $80 \mathrm{~s}(P<0.05)$ and in those in their $60 \mathrm{~s}$ vs those in their $70 \mathrm{~s}(P<0.01)$ or $80 \mathrm{~s}(P<0.05)$.

\section{Correlations of parameters in males and females}

Table 4 presents the results of the Pearson's correlation analysis of the parameters in the 252 males (upper diagonal line) and 320 females (lower diagonal line) included in this study. The results of the lumbar kyphosis angle and spinal inclination measurements are described in the following.
Males

The correlation between lumbar kyphosis angle and height ( $r=-0.131, P<0.05)$, body weight $(r=-0.126, P<0.05)$, back extensor strength $(r=-0.223, P<0.05)$, and thoracic kyphosis angle $(r=-0.273, P<0.0001)$ was significantly negative, as was the correlation between spinal inclination and grip strength $(r=-0.152, P<0.05)$, back extensor strength $(r=-0.240, P<0.05)$, and hip flexor strength $(r=-0.184$, $P<0.05)$, However, spinal inclination correlated positively with age $(r=0.160, P<0.05)$ and lumbar kyphosis angle $(r=0.388, P<0.0001)$.

Table 4 Pearson's correlation of parameters in 252 male (above the diagonal line) and 320 female (below the diagonal line) participants

\begin{tabular}{|c|c|c|c|c|c|c|c|c|c|c|c|c|c|}
\hline Characteristics & Age & Height & Weight & GS & BES & HFS & KES & TK & LK & SI & MTK & MLK & MSI \\
\hline Age & & $-0.400 * *$ & $-0.442^{* *}$ & $-0.512^{* *}$ & $-0.502^{* *}$ & $-0.389 * *$ & $-0.304 * *$ & 0.091 & 0.107 & $0.160^{*}$ & $-0.15 I^{*}$ & $-0.176 *$ & -0.076 \\
\hline Height & -0.49 I** & & $0.640 * *$ & $0.505^{* *}$ & $0.395 * *$ & $0.273 * *$ & $0.276 * *$ & -0.054 & $-0.131^{*}$ & 0.004 & 0.070 & -0.026 & -0.118 \\
\hline Weight & $-0.242 * *$ & $0.340 * *$ & & $0.564 * *$ & $0.522^{* *}$ & $0.359 * *$ & $0.300^{* *}$ & -0.091 & $-0.126^{*}$ & 0.031 & 0.096 & 0.055 & -0.076 \\
\hline GS & $-0.465^{* *}$ & $0.462^{* *}$ & $0.363 * *$ & & $0.559 * *$ & $0.34 I^{* *}$ & $0.360^{* *}$ & -0.064 & -0.117 & $-0.152 *$ & 0.093 & 0.065 & 0.025 \\
\hline BES & $-0.444 * *$ & $0.268 * *$ & $0.262^{* *}$ & $0.433^{* *}$ & & $0.367^{* *}$ & $0.346^{* *}$ & -0.055 & $-0.223^{*}$ & $-0.240 *$ & $0.143^{*}$ & $0.258 * *$ & $0.17 I^{*}$ \\
\hline HFS & $-0.242^{* *}$ & $0.199 *$ & $0.255^{* *}$ & $0.368 * *$ & $0.326 * *$ & & $0.764^{* *}$ & $-0.126 *$ & -0.025 & $-0.184 *$ & 0.106 & -0.032 & 0.005 \\
\hline KES & $-0.178^{*}$ & $0.178 *$ & $0.143 *$ & $0.262^{* *}$ & $0.259 * *$ & $0.684^{* *}$ & & -0.061 & 0.004 & -0.108 & $0.125 *$ & -0.012 & -0.032 \\
\hline TK & 0.014 & -0.060 & 0.065 & 0.039 & 0.035 & -0.086 & $-0.156^{*}$ & & $-0.273 * *$ & 0.017 & -0.048 & $0.142^{*}$ & 0.100 \\
\hline LK & 0.230 ** & $-0.128 *$ & -0.028 & $-0.176 * *$ & $-0.296 * *$ & $-0.121 *$ & -0.015 & $-0.284 * *$ & & $0.388 * *$ & -0.082 & $-0.154^{*}$ & $-0.162^{*}$ \\
\hline SI & $0.239 * *$ & $-0.130 *$ & 0.105 & $-0.121 *$ & $-0.198^{*}$ & $-0.187 *$ & $-0.114^{*}$ & -0.018 & $0.376^{* *}$ & & 0.016 & $-0.190^{*}$ & $-0.358 * *$ \\
\hline MTK & 0.014 & -0.015 & -0.058 & -0.035 & -0.051 & 0.082 & 0.018 & -0.003 & -0.009 & -0.077 & & $-0.130 *$ & 0.059 \\
\hline MLK & $-0.23 I^{* *}$ & $0.118^{*}$ & -0.007 & $0.121^{*}$ & $0.207^{*}$ & -0.060 & -0.061 & -0.039 & $-0.123^{*}$ & $-0.152 *$ & $-0.128 *$ & & $0.521^{* *}$ \\
\hline MSI & -0.100 & 0.045 & 0.052 & 0.088 & $0.203^{*}$ & -0.001 & -0.061 & 0.103 & $-0.131 *$ & $-0.27 \mid * *$ & 0.052 & $0.460 * *$ & \\
\hline
\end{tabular}

Notes: $* P<0.05, * * P<0.0001$.

Abbreviations: GS, grip strength; BES, back extensor strength; HFS, hip flexor strength; KES, knee extensor strength; TK, thoracic kyphosis angle; LK, lumbar kyphosis angle; SI, sacral inclination; MTK, mobility of the thoracic kyphosis angle; MLK, mobility of the lumbar kyphosis angle; MSI, mobility of the sacral inclination. 
Table 5 Factors affecting lumbar kyphosis and spinal inclination in the male and female study participants

\begin{tabular}{|c|c|c|c|c|}
\hline \multirow[t]{2}{*}{ Variables } & \multicolumn{2}{|l|}{ Lumbar kyphosis } & \multicolumn{2}{|l|}{ Spinal inclination } \\
\hline & $\begin{array}{l}\text { Regression } \\
\text { coefficient }(95 \% \mathrm{Cl})\end{array}$ & $P$-value & $\begin{array}{l}\text { Regression } \\
\text { coefficient }(95 \% \mathrm{Cl})\end{array}$ & $P$-value \\
\hline \multicolumn{5}{|l|}{ Male } \\
\hline Age, years & - & - & $0.011(-0.067,0.090)$ & 0.775 \\
\hline Height, cm & $-0.010(-0.353,0.153)$ & 0.438 & - & - \\
\hline Body weight, kg & $-0.002(-0.204,0.200)$ & 0.983 & - & - \\
\hline Grip strength, kg & & & $0.002(-0.089,0.092)$ & 0.971 \\
\hline Back extensor strength, $\mathrm{kg}$ & $-0.211(-0.346,-0.076)$ & 0.002 & $-0.042(-0.103,0.018)$ & 0.171 \\
\hline Hip flexor strength, kg & - & - & $-0.097(-0.191,-0.002)$ & 0.045 \\
\hline Thoracic kyphosis angle, degree & $-0.219(-0.308,-0.130)$ & $<0.0001$ & - & - \\
\hline Lumbar kyphosis angle, degree & - & - & $0.150(0.102,0.199)$ & $<0.000$ I \\
\hline \multicolumn{5}{|l|}{ Female } \\
\hline Age, years & $0.157(-0.010,0.325)$ & 0.066 & $0.087(0.011,0.162)$ & 0.025 \\
\hline Height, cm & $-0.042(-0.25 I, 0.167)$ & 0.691 & $-0.012(-0.105,0.082)$ & 0.807 \\
\hline Body weight, kg & $0.027(-0.232,0.286)$ & 0.836 & $0.060(-0.056,0.175)$ & 0.310 \\
\hline Grip strength, kg & $-0.109(-0.378,0.159)$ & 0.424 & $-0.011(-0.089,0.068)$ & 0.791 \\
\hline Back extensor strength, $\mathrm{kg}$ & $-0.308(-0.480,-0.136)$ & 0.001 & $-0.127(-0.283,-0.030)$ & 0.112 \\
\hline Hip flexor strength, kg & - & - & $-0.011(-0.139,0.118)$ & 0.870 \\
\hline Thoracic kyphosis angle, degree & $-0.191(-0.260,-0.122)$ & $<0.000$ I & - & - \\
\hline Lumbar kyphosis angle, degree & - & - & $0.149(0.101,0.198)$ & $<0.0001$ \\
\hline
\end{tabular}

Note: Results of a multiple regression analysis.

Abbreviation: $\mathrm{Cl}$, confidence interval.

\section{Females}

A significantly negative correlation between lumbar kyphosis angle and height $(r=-0.128, P<0.05)$, grip strength ( $r=-0.176, P<0.0001)$, back extensor strength $(r=-0.296$, $P<0.0001)$, hip flexor strength $(r=-0.121, P<0.05)$, and thoracic kyphosis angle $(r=-0.284, P<0.0001)$ was determined, whereas the correlation of the lumbar kyphosis angle with age $(r=0.230, P<0.0001)$ and spinal inclination $(r=0.388$, $P<0.0001)$ was significantly positive. Spinal inclination correlated positively with age $(r=0.239, P<0.0001)$ and lumbar kyphosis angle $(r=0.376, P<0.0001)$ and negatively with height $(r=-0.130, P<0.05)$, grip strength $(r=-0.121$, $P<0.05)$, back extensor strength $(r=-0.198, P<0.05)$, hip flexor strength $(r=-0.187, P<0.05)$, and knee extensor strength $(r=-0.114, P<0.05)$.

\section{Multiple regression analyses}

Multiple regression analyses were performed to determine the factors that influenced the lumbar kyphosis angle and spinal inclination in males and females. Variables demonstrating significant correlations with lumbar kyphosis angle and spinal inclination in the univariate analysis were included. The results showed that back extensor strength and thoracic kyphosis angle were significantly associated with the lumbar kyphosis angle in both sexes (Table 5). Hip flexor strength and lumbar kyphosis angle were significantly associated with spinal inclination in males, whereas in females, the factors significantly associated with spinal inclination were age and the lumbar kyphosis angle (Table 5).

\section{Discussion}

This study demonstrated that grip, back extensor, hip flexor, and knee extensor strength decrease significantly in elderly Japanese males and females. The accelerated decline in muscle strength that occurs with aging is well established. ${ }^{19,20}$ This study showed significantly less muscle strength in the upper and lower extremities in individuals in their 80s than in those in their 50s and 60s. Larsson et $\mathrm{al}^{21}$ reported that strength of the quadriceps was stable until age 40 years but began to decrease at the age of 50 years. Upper extremity power and strength are reduced by almost $30 \%$ in 60 -year-old people vs 20-year-old participants. ${ }^{22}$

In the group of elderly Japanese examined in this study, back extensor strength declined with age in both sexes, especially among individuals in their 70 s and $80 \mathrm{~s}$. A previous study determined an approximately $50 \%$ decline in lumbar extensor strength between the third and sixth decades of life. ${ }^{10}$ Other studies reported a decrease in trunk muscle strength in older adults ${ }^{23}$ and that back extensor strength decreases with aging, especially in the already elderly. However, sex-related differences in back extensor strength had not been previously investigated. Our study showed that 
back extensor strength decreased significantly with aging and was a significant predictor of lumbar kyphosis in both sexes, suggesting that a decrease in back extensor strength contributes to age-related lumbar kyphotic deformities in both males and females.

We also identified that age-related changes in spinal kyphosis angles, evaluated using the SpinalMouse, differed between sexes. Several studies have demonstrated an inverse correlation between spinal extensor muscle strength and thoracic hyperkyphosis. ${ }^{24,25}$ Among our patients, the decreased back extensor strength and increased thoracic kyphosis were significant factors associated with the lumbar kyphosis angle, both in males and in females. In the lumbar spine, fatty degeneration and volume loss of the paraspinal muscles are associated with degenerative kyphosis. ${ }^{26}$ The natural aging process affects all elements of the spine, including the intervertebral disks, facet joints, vertebral bodies, and supporting muscles and ligaments. ${ }^{27}$ Although these additional factors were not evaluated in this study we did find that the decrease in back extensor strength during aging was related to an increase in the lumbar kyphosis angle in both our male and our female participants.

Spinal inclination, which represents the degree of forward positioning of the trunk, increased significantly with age in our study population. In males, the lumbar kyphosis angle was significantly related to the increase in spinal inclination. In females, age, BMI, and lumbar kyphosis angle had a significantly positive relationship, and hip flexor strength a significantly negative relationship, with increased spinal inclination. Previous reports showed an association between spinal inclination and unstable body balance as well as an increased incidence of falls. ${ }^{9,28,29}$ Accordingly, the prevention of increased spinal inclination may contribute to decreasing the risk of falls. Spinal inclination is compensated not only by spinal extension but also by hip extension or knee flexion. In this study, increased hip flexor strength was associated with an increase in spinal inclination in females. Therefore, in this group, strengthening of both the back extensors and the lower extremities could be useful in preventing falls.

There were several limitations in this study. First, even though the $P$-values were $<0.05$, the correlation coefficients were weak to moderate, owing to the large sample size. Second, the number of male and female participants in the different age groups was not the same, which may have influenced the statistical analyses.

\section{Conclusion}

However, our results suggested significant decreases in grip strength, hip flexor strength, and knee extensor strength during aging in Japanese males and females. We also found a significant decrease in the lumbar, but not the thoracic, kyphosis angle during aging in females, whereas this was not the case in males. By contrast, spinal inclination increased significantly with aging in both sexes. Back extensor strength and thoracic kyphosis angle were significantly associated with the lumbar kyphosis angle in males and females. In males, the lumbar kyphosis angle and hip flexor strength had a significant effect on spinal inclination, whereas in females, spinal inclination was significantly associated with age and the lumbar kyphosis angle.

\section{Acknowledgment}

The authors thank Yumiko Kuwahara, Kazuko Kiuchi, and Eriko Kamada for their help in the data analysis.

\section{Disclosure}

The authors report no conflicts of interest in this work.

\section{References}

1. Doherty TJ. Invited review: aging and sarcopenia. J Appl Physiol. 2003;95(4):1717-1727.

2. Rogers MA, Evans WJ. Changes in skeletal muscle with aging: effects of exercise training. Exerc Sport Sci Rev. 1993;21:65-102.

3. Frontera WR, Hughes VA, Fielding RA, Fiatarone MN, Willaim JE, Roubenoff R. Aging of skeletal muscle: a 12-yr longitudinal study. J Appl Physiol. 2000;88(4):1321-1326.

4. Visser M, Goodpaster BH, Kritchevsky SB, et al. Muscle mass, muscle strength, and muscle fat infiltration as predictors of incident limitations in the well-functioning older persons. J Gerontol A Biol Sci Med Sci. 2005;60(3):324-333.

5. Lauretani F, Russo RC, Bandinelli S, et al. Age associated changes in skeletal muscles and their effect on mobility: an operational diagnosis of sarcopenia. J Appl Physiol (1985). 2003;95(5):1851-1860.

6. Rolland Y, Lauwers-Cances V, Cesari M, Vellas B, Pahor M, Grandjean H. Physical performance measures as predictors of mortality in a cohort of community-dwelling older French women. Eur J Epidemiol. 2006;21(2):113-122.

7. Rantanen T, Guralnik JM, Foley D, et al. Midlife hand grip strength as a predictor of old age disability. JAMA. 1999;281(6):558-560.

8. Miyakoshi N, Hongo M, Maekawa S, Ishikawa Y, Shimada Y, Itoi E. Back extensor strength and lumbar spinal mobility are predictors of quality of life in patients with postmenopausal osteoporosis. Osteoporos Int. 2007;18(10):1397-1403.

9. Kasukawa Y, Miyakoshi N, Hongo M, et al. Relationships between falls, spinal curvature, spinal mobility and back extensor strength in elderly people. J Bone Miner Metab. 2010;28(1):82-87.

10. Limburg PJ, Sinaki M, Rogers JW, Caskey PE, Pierskalla BK. A useful technique for measurement of back strength in osteoporotic and elderly patients. Mayo Clin Proc. 1991;66(1):39-44.

11. Sinaki M, Khosla P, Limburg PJ, Rogers JW, Murtaug PA. Muscle strength in osteoporotic versus normal women. Osteoporos Int. 1993; 3(1):8-12.

12. Fon GT, Pitt MJ, Thies AC Jr. Thoracic kyphosis: range in normal subjects. AJR Am J Roentgenol. 1980;134(5):979-983.

13. Boyle JJ, Milne N, Singer KP. Influence of age on cervicothoracic spinal curvature: an ex vivo radiographic survey. Clin Biomech (Bristol, Avon). 2002;17(5):361-367. 
14. Ensrud KE, Black DM, Harris F, Ettinger B, Cummings SR. Correlates of kyphosis in older women. The Fracture Intervention Trial Research Group. J Am Geriatr Soc. 1997;45(6):682-687.

15. Miyakoshi N, Itoi E, Kobayashi M, Kodama H. Impact of postural deformities and spinal mobility on quality of life in postmenopausal osteoporosis. Osteoporos Int. 2003;14(12):1007-1012.

16. Miyakoshi N, Hongo M, Maekawa S, et al. Factors related to spinal mobility in patients with postmenopausal osteoporosis. Osteoporos Int. 2005;16(12):1871-1874.

17. Post RB, Leferink VJM. Spinal mobility: sagittal range of motion measured with the SpinalMouse, a new non-invasive device. Arch Orthop Trauma Surg. 2004;124(3):187-192.

18. Murata K, Yano E. Medical Statistics for Evidence-Based Medicine with SPBS User's Guide. Tokyo: Nankodo; 2002.

19. Porter MM, Vandervoort AA, Lexell J. Aging of human muscle: structure, function, and adaptability. Scand J Med Sci Sports. 1995; 5(3):129-142.

20. Vandervoort AA. Aging of the human neuromuscular system. Muscle Nerve. 2002;25(1):17-25.

21. Larsson L, Grimby G, Karlsson J. Muscle strength and speed of movement in relation to age and muscle morphology. $J$ Appl Physiol Respir Environ Exerc Physiol. 1979;46(3):451-456.

22. Metter EJ, Conwit R, Tobin J, Fozard JL. Age-associated loss of power and strength in the upper extremities in women and men. J Gerontol A Biol Sci Med Sci. 1997;52(5):B267-B276.
23. Eagan MS, Sedlock DA. Kyphosis in active and sedentary postmenopausal women. Med Sci Sports Exerc. 2001;33(5):688-695.

24. Itoi E, Sinaki M. Effect of back-strengthening exercise on posture in healthy women 49 to 65 years of age. Mayo Clin Proc. 1994;69(11): 1054-1059.

25. Sinaki M, Itoi E, Rogers JW, Bergstralh EJ, Wahner HW. Correlation of back extensor strength with thoracic kyphosis and lumbar lordosis in estrogen-deficient women. Am J Phys Med Rehabil. 1996; 75(5):370-374.

26. Hyun SJ, Bae CW, Lee SH, Rhim SC. Fatty degeneration of paraspinal muscle in patients with the degenerative lumbar kyphosis: a new evaluation method of quantitative digital analysis using MRI and CT Scan. J Spinal Disord Tech. 2013. Epub 2013 Sep 3.

27. Fehlings MG, Tetreault L, Nater A, et al. The aging of the global population: the changing epidemiology of disease and spinal disorders. Neurosurgery. 2015;77(suppl 4):S1-S5.

28. Ishikawa Y, Miyakoshi N, Kasukawa Y, Hongo M, Shimada Y. Spinal sagittal contour affecting falls: cut-off value of the lumbar spine for falls. Gait Posture. 2013;38(2):260-263.

29. Imagama $\mathrm{S}$, Ito $\mathrm{Z}, \mathrm{Wakao} \mathrm{N}$, et al. Influence of spinal sagittal alignment, body balance, muscle strength, and physical ability on falling of middle-aged and elderly males. Eur Spine J. 2013;22(6):1346-1353.
Clinical Interventions in Aging

\section{Publish your work in this journal}

Clinical Interventions in Aging is an international, peer-reviewed journal focusing on evidence-based reports on the value or lack thereof of treatments intended to prevent or delay the onset of maladaptive correlates of aging in human beings. This journal is indexed on PubMed Central, MedLine,

\section{Dovepress}

CAS, Scopus and the Elsevier Bibliographic databases. The manuscript management system is completely online and includes a very quick and fair peer-review system, which is all easy to use. Visit http://www.dovepress. com/testimonials.php to read real quotes from published authors. 